\title{
Detection of Metallo-Beta-Lactamase Production among Klebsiella pneumoniae Isolates by Phenotypic Detection Methods
}

\author{
Rama Sikka, Meenu Garg, Kausalya Raghuraman* and Uma Chaudhary \\ Department of Microbiology, Pt. B.D. Sharma PGIMS, Rohtak, Haryana, India \\ *Corresponding author
}

\section{A B S T R A C T}

\section{Keywords}

Metallo-beta-lactamases,

Klebsiella pneumoniae,

Ceftazidime combined

disc test, Imipenem

combined disc test

Article Info

Accepted:

24 January 2018

Available Online:

10 February 2018
Resistance to carbapenems is an emerging problem among Klebsiella pneumoniae isolates. A simple and effective phenotypic detection method for carbapenemase production is required in health care settings. A total of 100 clinical isolates of Klebsiella pneumoniae from various samples were screened for imipenem resistance. The imipenem resistant strains were further tested for metallo-beta-lactamase (MBL) production by imipenem combined disc test and ceftazidime combined disc test. Among the 100 isolates, 62 isolates were imipenem resistant and of these 45 were MBL producers. Ceftazidime combined disc method alone could detect $24(53.3 \%)$, imipenem combined disc method alone could detect $12(26.6 \%)$ and nine $(20 \%)$ of the isolates were positive by both these methods. The present study highlights the burden of MBL producing Klebsiella pneumoniae in a North Indian tertiary care hospital. The study findings suggest that using ceftazidime combined disc test alone had a better yield of MBL when compared to imipenem combined disc test alone. However, combination of both the methods resulted in greater detection of MBL production.

\section{Introduction}

Klebsiella pneumoniae is a highly virulent organism, known to spread multidrug resistance in hospital setups.(Won SY et al., 2011) Klebsiella pneumoniae is responsible for hospital acquired urinary tract infections, bacteremia, pneumonia and intra-abdominal infections. (Lim SM et al., 2005) Multidrug resistant Klebsiella spp.is one of the major reasons for mortality and morbidity among hospitalized patients.

The increased use of carbapenems leads to emergence of the resistant strains and their outbreak in hospital setting. (Khajuria A et al., 2014) Resistance to carbapenems which are one of the last line in the management of infection is now emerging at an alarming rate. Acquired metallo-beta-lactamase is one of the worrisome resistance mechanisms owing to their capacity to hydrolyze the beta lactam class of antimicrobial agents with the exception of aztreonam. Since their genes are carried on a highly mobile element, it thus allows for their easy dissemination. (Walsh TR et al., 2005)

Resistance to carbapenems is an emerging problem among Klebsiella pneumoniae 
isolates. Phenotypic detection methods for carbapenemase detection are the need of the hour. Hence, the present study was conducted to explore the various phenotypic methods for the detection of metallo-beta-lactamase production among clinical isolates of Klebsiella pneumoniae.

\section{Materials and Methods}

This cross sectional study was conducted in Department of Microbiology, Post Graduate Institute of Medical Sciences, Rohtak, Haryana, India. A total of 100 clinical isolates of Klebsiella pneumoniae from various clinical samples (sputum, pus, blood, urine and high vaginal swabs) were included in the study. The antibiotic susceptibility testing was done on the isolates as per CLSI guidelines. (CLSI 2014)

\section{Combined disc methods}

Isolates showing reduced susceptibility to imipenem were further processed for MBL production by zone enhancement with EDTA impregnated imipenem and ceftazidime discs. Test organisms were impregnated on MHA plate.Two $10 \mu \mathrm{g}$ imipenem discs and two $30 \mu \mathrm{g}$ ceftazidime discs were placed on the inoculated plate and to one imipenem and ceftazidime disc $750 \mu \mathrm{g}$ of EDTA was added. The plates were incubated at $35^{\circ} \mathrm{C}$ for $16-18$ hours. Zone size enhancement of $\geq 7 \mathrm{~mm}$ for ceftazidime EDTA disc compared to ceftazidime alone and a zone enhancement of $\geq 7 \mathrm{~mm}$ for imipenem EDTA disc compared to imipenem disc alone was taken as a positive criterion for MBL production (Yong et al., 2002; Galani et al., 2008)

\section{Statistical analysis}

The data was collected and analysed by using Chi-square test. A ' $p$ ' value of $<0.05$ was considered as statistically significant and $p$ value of $<0.001$ was considered as highly significant.

\section{Results and Discussion}

The study involved a total of 100 consecutive, clinical isolates of Klebsiella pneumoniae from various clinical samples for a period of one year. Infection were detected in blood $(41 \%)$, followed by $\operatorname{pus}(27 \%)$, urine $(26 \%)$, sputum (4\%) and high vaginal swabs $(2 \%)$. A total of $80(80 \%)$ isolates were from inpatients and $20(20 \%)$ were from outpatients. Table 1 shows the sample wise distribution of $K$. pneumoniae among indoor and outdoor patients.

\section{Susceptibility pattern of the isolates}

The susceptibility pattern of isolates among metallo-beta-lactamase producers and nonmetallo-beta-lactamase producers is mentioned in Table 2. Among the Klebsiella pneumoniae isolates highest resistance was for cephalosporins. Second generation cephalosporins, cefoxitin and cefuroxime showing 93\% resistance, third generation cephalosporins that is ceftazidime $94 \%$, cefotaxime $93 \%$ and ceftriaxone $83 \%$ and fourth generation cephalosporin cefepime showing $95 \%$ resistance, respectively.

Among the carbapenems least resistance was for ertapenem $56 \%$, followed by imipenem $62 \%$ and meropenem $70 \%$ (Table 2). Resistance to imipenem and meropenem was more among MBL producers than non MBL producers and was found to be statistically highly significant. ( $\mathrm{p}$ value $<0.001$ ). Reduced susceptibility to imipenem was shown by 62 isolates and these were further processed for metallo-beta-lactamase production.

Metallo-beta-lactamase detection was done by combined disc method using imipenem and ceftazidime disc. 
Table.1 Distribution of Klebsiella pneumoniae isolates among indoor and outdoor patients

\begin{tabular}{|c|c|c|c|c|c|c|}
\hline \multirow[t]{2}{*}{$\begin{array}{l}\text { Type of } \\
\text { sample }\end{array}$} & \multicolumn{2}{|c|}{$\begin{array}{l}\text { k. pneumoniae strains } \\
\text { isolated in indoor } \\
\text { patients } n=80\end{array}$} & \multicolumn{2}{|c|}{$\begin{array}{l}\text { k. pneumoniae strains } \\
\text { isolated in outdoor } \\
\text { patients } n=20\end{array}$} & \multicolumn{2}{|c|}{ Total } \\
\hline & No. & $\%$ & No. & $\%$ & No. & $\%$ \\
\hline Blood & 40 & 50 & 1 & 5 & 41 & 41 \\
\hline Pus & 25 & 31.2 & 2 & 10 & 27 & 27 \\
\hline Urine & 10 & 12.5 & 16 & 80 & 26 & 26 \\
\hline Sputum & 3 & 3.75 & 1 & 5 & 4 & 4 \\
\hline HVS* & 2 & 2.5 & 0 & 0 & 2 & 2 \\
\hline TOTAL & 80 & 100 & 20 & 100 & 100 & 100 \\
\hline
\end{tabular}

*HVS- high vaginal swabs

Table.2 Comparison of antimicrobial resistance pattern of MBL and non MBL producing $K$. pneumoniae strains to various antibiotics

\begin{tabular}{|c|c|c|c|c|c|c|c|}
\hline \multirow[t]{2}{*}{$\begin{array}{l}\text { Antimicrobial } \\
\text { drugs }\end{array}$} & \multicolumn{2}{|c|}{ Resistant isolates } & \multicolumn{2}{|c|}{$\begin{array}{l}\text { MBL producer } \\
\quad \mathbf{N}=45\end{array}$} & \multicolumn{2}{|c|}{$\begin{array}{l}\text { MBL non producer } \\
\qquad \begin{array}{l}\mathrm{N}=55\end{array}\end{array}$} & \multirow[t]{2}{*}{$P$ value } \\
\hline & No. & $\%$ & No. & $\%$ & No. & $\%$ & \\
\hline \multicolumn{8}{|c|}{$\beta$-lactams } \\
\hline Ampicillin & 87 & 87 & 38 & 84.4 & 49 & 89 & 0.6976 \\
\hline ceftazidime & 94 & 94 & 43 & 95.5 & 51 & 92.7 & 0.8656 \\
\hline cefepime & 95 & 95 & 42 & 93.3 & 53 & 96.3 & 0.8176 \\
\hline ceftriaxone & 83 & 83 & 41 & 91.1 & 42 & 76.3 & 0.0919 \\
\hline cefoxitin & 93 & 93 & 44 & 97.7 & 49 & 89 & 0.1936 \\
\hline cefuroxime & 93 & 93 & 43 & 95.5 & 50 & 90.9 & 0.6086 \\
\hline cefotaxime & 93 & 93 & 43 & 95.5 & 50 & 90.9 & 0.6086 \\
\hline aztreonam & 82 & 82 & 36 & 80 & 46 & 83.6 & 0.8342 \\
\hline imipenem & 62 & 62 & 45 & 100 & 17 & 30.9 & 0.0001 \\
\hline meropenem & 70 & 70 & 44 & 97.7 & 26 & 47.2 & 0.0001 \\
\hline ertapenem & 56 & 56 & 30 & 66.6 & 26 & 47.2 & 0.0816 \\
\hline $\begin{array}{c}\text { Amoxicillin- } \\
\text { clavulanic acid }\end{array}$ & 84 & 84 & 36 & 80 & 48 & 87.2 & 0.4760 \\
\hline $\begin{array}{l}\text { Ampicillin } \\
\text { sulbactam }\end{array}$ & 88 & 88 & 42 & 93.3 & 46 & 83.6 & 0.2399 \\
\hline $\begin{array}{c}\text { Ticarcillin } \\
\text { clavulanic acid }\end{array}$ & 90 & 90 & 40 & 88.8 & 50 & 90.9 & 0.7376 \\
\hline $\begin{array}{l}\text { Piperacillin } \\
\text { tazobactam }\end{array}$ & 77 & 77 & 39 & 86.6 & 38 & 69 & 0.0659 \\
\hline \multicolumn{8}{|c|}{ Fluoroquinolones } \\
\hline ciprofloxacin & 83 & 83 & 38 & 84.4 & 45 & 81.8 & 0.9360 \\
\hline levofloxacin & 84 & 84 & 39 & 86.6 & 45 & 81.8 & 0.7011 \\
\hline \multicolumn{8}{|c|}{ Aminoglycosides } \\
\hline Amikacin & 75 & 75 & 35 & 77.7 & 40 & 72.7 & 0.7277 \\
\hline gentamicin & 83 & 83 & 41 & 91.1 & 42 & 76.3 & 0.0919 \\
\hline \multicolumn{8}{|c|}{ Others } \\
\hline $\begin{array}{l}\text { Trimethoprim } \\
\text { sulfamethoxazole }\end{array}$ & 81 & 81 & 40 & 88.8 & 41 & 74.5 & 0.1181 \\
\hline
\end{tabular}


Table.3 Evaluation of combined disc method using imipenem and ceftazidime disc for detection of MBL production

\begin{tabular}{|c|c|c|}
\hline Method & Number & percentage \\
\hline MIBL producer by CDT using imipenem disc alone & 12 & 26.6 \\
\hline MIBL producer by CDT using ceftazidime disc alone & 24 & 53.3 \\
\hline MIBL producer by CDT using both imipenem and ceftaridime disc & 9 & 20 \\
\hline Total MIBL producer & 45 & 100 \\
\hline
\end{tabular}

Table 3 compares the combined disc method using imipenem and ceftazidime disc test. Ceftazidime combined disc method alone could detect 24(53.3\%), imipenem combined disc method alone could detect 12 (26.6\%) and nine $(20 \%)$ of the isolates were positive by both these methods.

The present study found highest resistance was for cephalosporins and least resistance for carbapenems among clinical isolates of Klebsiella pneumoniae. The study also highlights that ceftazidime combined disc test was a better method for metallo-betalactamase detection compared to imipenem combined disc test.

Rampant use of antimicrobial agents often leads to emergence of multidrug resistant Klebsiella pneumoniae isolates. Emergence of these multidrug resistant pathogens leads to an increasing need for newer antimicrobial discoveries. With only a few drugs left for treatment of the isolates we will reach a dead end soon (George PC et al., 2008). Infections caused by these resistant strains leads to prolonged hospital stay and increased health care cost for patients. (Nordmann $\mathrm{P}$ et al., 2009).

In the current study resistance to cephalosporins like cefoxitin, cefuroxime, cefotaxime, ceftriaxone, ceftazidime and cefepime was 93\%, 93\%, 93\%, 83\%, 94\% and $95 \%$.The resistance pattern is lower in study done by Kumar where he have observed $47.7 \%$ resistance to cefepime, $76.4 \%$ resistance to cefuroxime and $52.8 \%$ resistance to cefotaxime (Kumar, 2013). Mehrgan et al., had shown $84.7 \%$ resistance to ceftazidime and $86.6 \%$ resistance to cefotaxime which are comparable to present study. (Mehrgan et al., 2010) Resistance to amikacin and gentamicin was $75 \%$ and $83 \%$ respectively in the present study. Comparable results were seen in a study by Mehragn et al., who showed $72.8 \%$ and $78.2 \%$ respectively (Mehrgan et al., 2010). The difference in antimicrobial susceptibility could be due to varied geographical location and the commonly used antimicrobials in the setup.

The rate of MBL production ranges from 9.5$100 \%$. In the present study MBL production was $45 \%$. Studies done in North India showed a rate of $9.5 \%$ and that in Central India showed a rate of $100 \%$.(Seema K et al.,2011; Bora A et al.,2014; Khajuria A et al., 2014). This variation could be due to use of difference in the use of carbapenems in the setup.

Resistance to MBL producers were more compared to non MBL producers for antibiotics ceftriaxone (91.1\%, 76.3\%), cefoxitin $(97.7 \%, 89 \%)$, imipenem $(100 \%$, $30.9 \%)$, meropenem $(97.7 \%, 47.2 \%)$, piperacillin-tazobactam $\quad(86.6 \%, \quad 69 \%)$, gentamicin $(91.1 \%, \quad 76.3 \%)$ and cotrimoxazole $(88.8 \%, 74.5 \%)$. Resistance to imipenem and meropenem was more among MBL producers than non MBL producers and was found to be statistically highly significant. ( $\mathrm{p}$ value $<0.001$ ) 
Combined disc method using ceftazidime combined disc alone could detect 24(53.3\%) compared to $12(26.6 \%)(46.7 \%)$ by imipenem combined disc test alone in the current study. Nine isolates were MBL producers by both the methods. Pandya et al., in their study found imipenem combined disc test could detect $96.3 \%$ compared to ceftazidime combined disc test $(85.19 \%)$. (Pandya NP et al., 2011) Though our study shows ceftazidime combined disc method a better method, more studies are required to rationalize this finding.

The present study highlights the burden of MBL producing Klebsiella pneumoniae in a North Indian tertiary care hospital. Phenotypic detection methods are required in health care centers as genotyping would not be feasible is most healthcare setting. We believe that combination of both the methods resulted in greater detection of MBL production. A simple and inexpensive phenotypic method would help in rapid identification of MBL producer. Lastly, a combined effort of clinicians and microbiologist with a good antibiotic stewardship in hospitals will help in preventing the spread of these resistant bug.

\section{References}

Bora A, Sanjana R, Jha BK, Mahaseth SN and Bora KP.2014. Incidence of metallo- $\beta$ lactamase producing clinical isolates of Escherichia coli and Klebsiella pneumoniae in central Nepal. BMC Research Notes.7:557-63.

CLSI 2014. pdf (WWW Document), n.d. Google Docs. Performance Standards for Antimicrobial Susceptibility Testing; Twenty-Fourth Informational Supplement. CLSI document M100S24. Wayne, PA: Clinical and Laboratory Standards Institute.
Galani I, Rekatsina PD, Hatzaki D, Plachouras D, Souli M ang Giamarellou H. 2008.Evaluation of different laboratory tests for the detection of metallo-beta-lactamase production in Enterobacteriaceae. J Antimicrob Chemother.61:548-53.

George PC and Salmond MW.2008. "Antibiotic resistance: adaptive evolution". The Lancet. 372:97-103.

Khajuria A, Praharaj AK, Kumar M, Grover $\mathrm{N}$ and Aggarwal A. 2014.Multidrug resistant NDM-1 metallo-betalactamase producing Klebsiella pneumoniae sepsis outbreak in a neonatal intensive care unit in a tertiary care centre at central India. Indian $\mathbf{J}$ Pathol.Microbiol. 57:65-8

Kumar AR.2013. Antimicrobial sensitivity pattern of Klebsiella pneumoniae isolated from sputum from tertiary care hospital, Surendranagar, Gujarat and issues related to the rational selection of Antimicrobials. Sch J App Med Sci ; 1: 928-33.

Lim SM and Webb SAR.2005. Nosocomial bacterial infection in intensive care units: Organisms and mechanism of antibiotic resistance. Anaesthesia.60:887-902.

Mehrgan H, Rahbar M and Zohreh AH.2010. High prevalence of extended spectrum beta lactamase producing Klebsiella pneumoniae in a tertiary care hospital in Tehran, Iran. J Infect Dev Ctries. 4: 132-8.

Nordamann P, Cuzon G and Naas T.2009. "The real threat of Klebsiella pneumoniae carbapenemase producing bacteria". Lancet Infect Dis. 9:228-36.

Pandya NP, Prajapati SB, Mehta SJ, Kikani KM and Joshi PJ. 2011. Evaluation of various methods for detection of MBL production in gram negative bacilli. Int J Biol Med Res.3: 775-7. 
Seema K, Sen MR, Upadhyay $S$ and Bhattacharjee A.2011. Dissemination of the New Delhi metallo $\beta$ lactamase-1 (NDM-1) among Enterobacteriaceae in a tertiary referral hospital in North India. J Antimicrob Chemother. 66:1646-7.

Walsh TR, Toleman MA and Poirel L.2005. Metallo $\beta$-lactamases: the quiet before the storm? ClinMicrobiol Rev. 18:30625.

Won SY, Munoz-Price LS, Lolans K, Hata B, Weinstein RA and Hayden MA. 2011.
Emergence and rapid regional spread of Klebsiella pneumoniae carbapenemase producing Enterobacteriaceae. Clin Infect Dis.53:532-40.

Yong D, Lee K, Yum JH, Shin HB, Rossolini GM and Chong Y. 2002. Imipenem EDTA disk method for differentiation of metallo- $\beta$-lactamases producing clinical isolates of Pseudomonas spp. And Acinetobacter spp. J ClinMicrbiol. 40:3798-801.

\section{How to cite this article:}

Rama Sikka, Meenu Garg, Kausalya Raghuraman and Uma Chaudhary. 2018. Detection of Metallo-Beta-Lactamase Production among Klebsiella pneumoniae Isolates by Phenotypic Detection Methods. Int.J.Curr.Microbiol.App.Sci. 7(02): 2864-2869. doi: https://doi.org/10.20546/ijcmas.2018.702.349 